\title{
EXPECTATIVAS DE INTERAÇÃO ENTRE O SUPERVISOR PEDAGÓGICO E O PROFESSOR: CONTROLE OU AUTONOMIA ${ }^{1}$
}

\section{EXPECTATIONS ABOUT THE INTERACTIONS BETWEEN TEACHING SUPERVISORS AND TE- ACHERS: CONTROL OR AUTONOMY}

\author{
Aparecida Alice BARBOSA* \\ Cínara Gomes da SILVA** \\ Sulamita Coelho Ribeiro do NASCIMENTO ${ }^{* * *}$
}

Resumo: O presente trabalho apresenta a análise de uma produção investigativa sobre a expectativa de interação entre o supervisor pedagógico e o professor e a influência dessa relação no que diz respeito ao trabalho pedagógi$\mathrm{co}$, tomando como referência as décadas de 70 e 2000 , numa escola pública estadual de Barbacena - MG. A pesquisa foi desenvolvida através do levantamento de dados, com pressupostos de análise qualitativa, realizando descrições detalhadas de entrevistas semi-estruturadas com os atores participantes. Num primeiro momento, expõe um breve histórico sobre o lugar que o supervisor tem ocupado na educação desde a implementação da profissão como habilitação, para depois desenvolver, de maneira sucinta, a análise das entrevistas, discutindo os resultados à luz da literatura especializada. O sentido do controle, que reveste a função do supervisor na década de 70 , foca a presença fiscalizadora do trabalho desenvolvido pelo professor quanto às questões técni-

\footnotetext{
${ }^{1}$ Esta produção é resultado da pesquisa "Expectativa de interação entre o supervisor pedagógico e o professor: controle ou autonomia", realizada em uma escola pública estadual, com apoio da Pró-reitoria de Pesquisa, Extensão, Pós-Graduação e Cultura - PROPE/UNIPAC e da Fundação Nacional de Desenvolvimento do Ensino Superior Particular - FUNADESP.

${ }^{*}$ Mestre em Educação pela UCP. E-mail: apalicebarbosa@yahoo.com.br.

${ }^{* *}$ Acadêmica de Pedagogia da FAFI/UNIPAC. E-mail: cinaragomes@oi.com.br

${ }^{* * *}$ Acadêmica de Pedagogia da FAFI/UNIPAC. E-mail: pastor.renato@hotmail.com
} 
Expectativas de Interação entre o supervisor pedagógico e o professor: controle ou autonomia

cas e metodológicas, o que torna a relação supervisor/ professor objeto de rejeição dos professores. Atualmente essa relação é objeto de desejo, por representar uma possibilidade de trabalho coletivo e solidário, pela via da autonomia.

Palavras-chave: Supervisão Pedagógica. Professor. Controle. Autonomia.

Abstract: We're talking about an important performance to analyse or to do good investigation on pedagogic supervisor and teacher's work acting together in a public school. They are considering the years 70s and 2000s. The school is an specific one based in Barbacena-MG. Brazil. We wish to analyse the quality and describe all detail involved on it. Moreover having an private interprise with interested people that take part of that process. We invited them to answer some questions. At first we discussed the supervisor career from the beginning as an educator and an able professional. Afterwards we're going to study an interview related on suitable right as the same a matter of opinion. We have to say that in the 70s years Pedagogic Supervisor was at school to observe, examining teacher's performance. Later as a guide for methods and techinique. At this time teachers looked them almost as an enemy. They didn't like such situation. It wasn't confortable. But now a day, from now on they have good relationship. The interchange of ideas and experiences got a better school, encreased it. It is a way to help each other. Now everybody is working together. There is no dependence between them. There is autonomy, beautiful results and control. Maybe this is the way to get better and better like our students deserve.

Keywords: Teaching Supervision. Teacher. Control. Autonomy. 
Aparecida A. BARBOSA; Cínara Gomes da SILVA; Sulamita C. R. do NASCIMENTO

\section{INTRODUÇÃO}

O presente trabalho apresenta o resultado de uma pesquisa desenvolvida numa escola pública estadual que ministra o Ensino Fundamental e Ensino Médio, na cidade de Barbacena, Minas Gerais, durante o ano de 2008, com a meta de investigar a relação do supervisor pedagógico e o professor, na tentativa de conhecer as expectativas desses profissionais e, decorrentemente, compreender a razão de uma ação supostamente conjunta e analisar sua influência no trabalho pedagógico como um todo.

Investigando as relações existentes entre o supervisor pedagógico e o professor, pretende-se verificar o impacto do trabalho desse especialista no trabalho do professor. Entende-se que ao supervisor cabe organizar o trabalho de forma coletiva, para que o professor, como sujeito político, assuma sua responsabilidade perante os alunos e o significado integral do conteúdo. Acredita-se ainda que, por meio do trabalho coletivo e conjunto, o supervisor tenha oportunidade de favorecer e participar da formação continuada do professor, adequada à realidade da escola em que atua.

Freitas (apud SMYTH, 1999) comenta que o que se vê surgir como modelo em educação é o desenvolvimento de formas participativas em um ambiente no qual a política vem sendo traçada fora da escola e os professores vêm sendo incorporados apenas para implementar os detalhes. O autor critica isso e defende a ideia de que os professores deveriam modificar suas práticas à luz de suas reflexões sobre a própria prática, e não serem excluídos das discussões de política curricular.

Houve tempo em que o planejamento vinha pronto da Secretaria de Educação do estado, assim como os tipos de avaliações. Competia aos professores repassar a matéria. Essa dicotomia entre planejamento e execução em educação no Brasil é herança da educação jesuítica, que se estendeu pelos séculos seguintes.

Se desejarmos buscar uma integração de esforços e um professor participativo, ativo e criativo, logo em sua formação docente, é importante destacar que, segundo Moreira (2002, p. 45-46), "formar um professor técnica e politicamente competente significa formar um professor que integre, em sua atuação, conhecimentos, habilidades, crenças, valores, emoções e comprometimentos". Portanto, o professor não pode mais ser considerado um mero "executor de projetos" elaborado por terceiros. 
Expectativas de Interação entre o supervisor pedagógico e o professor: controle ou autonomia

Acreditamos que a transformação da prática depende da participação do professor de forma integral e contínua em todas as etapas do processo de produção e transmissão do conhecimento, e da autonomia adquirida no próprio processo de participação. E essa crença, advinda da vivência, identifica-se com o pensamento de Bobbio, citado por Ferreira (2002, p. 252), ao definir o indivíduo participativo como "aquele que contribui direta ou indiretamente para uma decisão política".

Pela participação e pela união no processo educacional, o supervisor e o professor assumem o compromisso com o ensino, cuja qualidade passa, também, a resultar da relação recíproca e solidária dos agentes educacionais.

A proposta desta pesquisa vem somar-se às inúmeras possibilidades oferecidas pelo curso de Pedagogia da FAFI - UNIPAC, além de se encontrar em consonância com os objetivos gerais do curso e o perfil do pedagogo que se pretende formar. E para chegar a esse perfil e estar ao mesmo tempo de acordo com as Diretrizes Curriculares para o curso de Pedagogia, foram estabelecidas análises e discussões sobre o tema. A prática da supervisão exige, da parte do supervisor, uma constante avaliação crítica de seu próprio desempenho e um esforço continuado de aperfeiçoamento não somente como técnico, mas especialmente como articulador. Para isso, deverá cultivar um maior grau de efeito interativo, condição de mobilização das energias dos professores no sentido dos objetivos educacionais pretendidos.

É na abertura desse diálogo sobre a postura e o papel do supervisor pedagógico que estaremos proporcionando a esse profissional uma reflexão, e instrumentalizando os alunos para entrarem em contato com um ensino de qualidade capaz de realizar as diversas relações entre teoria, prática e ciência.

Acreditamos que contribuindo com a identificação do perfil, ou da identidade do supervisor, é possível contribuir para uma reflexão mais acurada sobre o papel do supervisor junto aos alunos do curso de Pedagogia e profissionais da área. Por isso, além desse, constituem objetivos específicos desta pesquisa: identificar as tendências que nortearam o trabalho da supervisão pedagógica nas décadas de 1970 e 2000; comparar as funções antes exercidas (década de 1970) com as atuais (década de 2000); identificar o que a Secretaria de Educação orientava aos supervisores como tarefa prioritária nas décadas de 1970 e 2000; analisar as concepções atuais que sustentam a ação profissional do supervisor. 
Inicialmente, apresenta-se neste trabalho a metodologia aplicada, como participantes, instrumentos, procedimentos e transcrição do material. Em seguida, encontra-se a revisão bibliográfica que deu suporte a esta pesquisa, esclarecendo conceitos importantes e traçando um breve histórico sobre o lugar que o supervisor tem ocupado na educação desde a implementação da profissão como habilitação, pelo Parecer 252/69, incorporado à Resolução $n^{\circ} 2$, de 18 de maio de 1969. Posteriormente, analisa-se o momento atual da profissão, no seu aspecto formal, orientado pelo Título VI da Lei 9394/96. No aspecto dinâmico, a supervisão será analisada pela relação que estabelece com o professor, vivida no cotidiano de uma escola pública estadual que trabalha com o Ensino Fundamental e o Ensino Médio. Essa análise será feita através do estudo das entrevistas, discutindose os resultados à luz das teorias revisadas. E, finalmente, serão apresentadas as considerações finais.

\section{METODOLOGIA}

A escolha de uma escola pública estadual para a pesquisa justifica-se porque, além de essa instituição contar com o trabalho do profissional "supervisor pedagógico" nos dois períodos a serem pesquisados, a supervisão faz parte, oficialmente, das ações pedagógicas desenvolvidas nas escolas estaduais, sendo o cargo preenchido por concurso público. $\mathrm{O}$ fato de a escola ter exercido suas atividades nos anos 70 foi também decisivo nessa escolha, pois a pesquisa busca analisar a interação entre os supervisores e os professores em dois momentos históricos: décadas de 70 e 2000.

A década de 70 foi indicada por ser a primeira após a implementação oficial da profissão no então $1^{\circ}$ grau, com a aprovação do Parecer 252/69 e a orientação propiciada, em termos educacionais, pela Lei de Diretrizes e Bases da Educação $n^{\circ} 5692$, de 11 de agosto de 1971. Já a década de 2000 justifica-se pela implementação da Lei de Diretrizes e Bases da Educação Nacional n 9394, de 20 de dezembro de 1996, cujo Título VI regulamenta a formação dos "Profissionais da Educação", e da Resolução CNE/CP no 1, de 15 de maio de 2006, que institui as Diretrizes Curriculares Nacionais para o Curso de Graduação em Pedagogia.

Professores, supervisores e diretores, representantes dos dois períodos, participaram da pesquisa, levando-se em conta o envol- 
Expectativas de Interação entre o supervisor pedagógico e o professor: controle ou autonomia

vimento desses atores no processo relacional do professor com o supervisor. Além da consideração ao período em que trabalharam na escola, a escolha apoiou-se também na variável disponibilidade desses profissionais.

Dessa forma foram selecionados sete professores, sendo que três são os mais antigos da escola e, dentre eles, dois são aposentados, mas se dispuseram a participar deste estudo; outros dois professores são profissionais há mais de vinte e cinco anos e as duas professoras restantes têm mais de vinte anos de profissão.

Quanto às supervisoras, foram entrevistadas quatro: uma do período inicial (esta não se encontra mais na escola, pois já se aposentou) e três do outro período, sendo responsáveis pelas séries finais do Ensino Fundamental, Ensino Médio e EJA. Três diretores, dois dos quais se encontram aposentados, também participaram das entrevistas.

Para salvaguardar a identidade dos atores, achamos por bem usar nomes fictícios. Quanto à escola, decidimos tratá-la simplesmente como escola pública estadual.

\section{UM BREVE HISTÓRICO}

O levantamento bibliográfico se deu em torno de temas relativos ao objeto de pesquisa - a relação entre o supervisor pedagógico e o professor: controle ou autonomia - e foi marcado pela trajetória da Supervisão Pedagógica.

As ideias de supervisão e de educação podem estar diretamente relacionadas. Ao buscarmos na história a gênese da supervisão, não encontramos referências explícitas ao termo ou à função, no entanto constatamos que a ideia de supervisão está presente no contexto educacional desde o início da Época Moderna, quando acontece a transformação dos modos de produção, a instauração do Capitalismo e o surgimento da escola pública para as massas.

É importante ressaltar que essa dominação da sociedade capitalista acontece em todas as instâncias. A respeito disso, Marcuse (1982, p. 37) faz a seguinte observação:

[...] a dominação - disfarçada em afluência e liberdade - se estende a todas as esferas da vida pública e privada, integra toda oposição autêntica, absorve todas as 
Aparecida A. BARBOSA; Cínara Gomes da SILVA; Sulamita C. R. do NASCIMENTO

alternativas. A racionalidade tecnológica revela o seu caráter político ao se tornar o grande veículo de melhor dominação, criando um universo verdadeiramente totalitário no qual sociedade e natureza, corpo e mente são mantidos num estado de permanente mobilização para a defesa desse universo.

Como vemos, o aparato tecnológico capitalista é montado para que as pessoas vejam as coisas pelo mesmo ângulo, por isso a integração também é cultural.

Nesse contexto, a supervisão surge como elemento de fiscalização e de controle

[...] os padrões de supervisão, baseados em inspeção e fiscalização, dão ênfase a um sistema vertical de autoridade, submissão e controle, e identifica-se como uma posição hierárquica, onde o executor é sempre um dependente e deve aceitar passivamente as diretrizes emanadas do supervisor, hierarquicamente num escalão mais alto. (LACERDA, 1983 p. 32).

Entretanto, entendemos que se encontra aí um ponto contraditório; situando a supervisão no nível hierárquico das decisões e a supervisão enquanto prática, ela se situa na linha também de execução, isto é, dos que obedecem e simplesmente executam as ordens que lhes são transmitidas.

Na década de 70, durante o governo militar, o Brasil importou tecnologia inclusive para a educação, através de convênios estabelecidos com os Estados Unidos. Com a Lei $5692 / 71$ para o $1^{\circ}$ e $2^{\circ}$ graus, a supervisão escolar é concebida, conforme Silva Júnior (2003, p. 93), "como parte de um processo de dependência cultural e econômica e integrada a seguir a um projeto militarista-tecnocrático de controle do povo e da nação [...]". A supervisão praticada produzia o ofuscamento e não a elaboração da vontade dos profissionais.

Arroyo enfatiza que essa lei veio para descaracterizar a chamada arte educativa:

A Lei $\mathrm{n}^{\circ} 5692$ de 71 descaracterizou a escola e os currículos de formação. As licenciaturas desfiguraram seus 
Expectativas de Interação entre o supervisor pedagógico e o professor: controle ou autonomia

mestres. Os currículos gradeados e disciplinares empobreceram o conhecimento, a escola e os professores. O peso central dado ao domínio dos conteúdos das áreas de licenciatura e o peso secundário dados ao domínio das artes educativas reflete essa mesma concepção e trato descaracterizado do ofício e do campo educativo que vem se alastrando há décadas. Reduzimos a escola, o ensino e os mestres a ensinantes. (ARROYO, 2000, p. 23).

Para Silva Júnior (2003), o controle que caracteriza a supervisão é uma consequência negativa das condições do momento histórico em que a profissão começou a existir no Brasil. A conotação negativa dada pelo autor à categoria de controle aparece na definição da palavra, enquanto analisada sob a perspectiva da relação entre supervisor e professor. Conforme descrita no dicionário, a palavra controle significa "[...] fiscalização sobre as atividades de pessoas, órgãos, departamentos ou sobre produtos, etc. para que tais atividades, ou produtos, não se desviem das normas preestabelecidas". (FERREIRA, 1986). Dessa forma, o controle pode ser interpretado como uma manifestação de poder que permeia a relação do supervisor com o professor, tornando esses atores do ensino profissionais distanciados hierarquicamente e vinculados a compromissos diferentes: o primeiro com o sistema e o segundo com o aluno.

Considerando as diferentes terminologias atribuídas à supervisão ao longo de sua existência, assim como suas diferentes significações e abrangências, faz-se necessário conhecê-las para, então, eleger aquela adequada à proposta de um estudo relacional.

O Parecer 252/69 e a Resolução 02/69, ambos do Conselho Federal de Educação, utilizam a expressão "Supervisão Escolar", a qual permaneceu até 1996, quando a profissão foi renomeada pela Lei de Diretrizes e Bases n ${ }^{\circ}$ 9394, de 20/12/96. Essa lei utiliza a terminologia "Supervisão Educacional" (Título VI, Art. 64), com o objetivo de ampliar as possibilidades de atuação do supervisor no mercado de trabalho e por considerar que hoje os serviços de tal profissional não se restringem ao âmbito escolar (ao contrário, se ampliam). Organizações de trabalho coletivo, sejam escolares ou não escolares, geralmente demandam articulação de atividades, integração, direção, orientação e coordenação. Todas as funções que podem ser consideradas como definidoras do trabalho de supervisão sofreram uma adequação ao modelo tecnicista de ensino. 
Aparecida A. BARBOSA; Cínara Gomes da SILVA; Sulamita C. R. do NASCIMENTO

Silva Júnior (1986, p.100) refere-se à Supervisão escolar como aquela que "se apresenta como mais uma tarefa cujo desempenho impõe aos seus praticantes a observância de um desempenho preciso do 'papel' a ser executado".

Rangel (2000) atribui significados diferenciados para os dois termos, educacional e escolar. Supervisão Educacional, segundo Ferreira $(2002$, p. 76$)$,

uma conotação abrangente extrapola as atividades da escola para alcançar, em nível macro, os aspectos estruturais, sistêmicos, da educação. Já Supervisão Escolar supõe a supervisão da escola nos seus aspectos administrativos, de funcionamento geral e pedagógico. Pouco identificada em relação ao ensino.

O termo coordenador também é amplamente utilizado. Na maioria das vezes a referência ao coordenador aborda uma das atribuições da supervisão, a de coordenar o projeto educacional. Para assumir essa coordenação não é necessário um supervisor habilitado, pois é uma função que pode ser exercida por qualquer professor. Logo, destaca-se aí a questão da formação.

Esse lugar de coordenador, integrante do grupo, é relativamente recente na história da organização escolar. É uma mudança de postura político-pedagógica que tomou força e abrangência, concomitantemente e em decorrência dos movimentos de redemocratização do país.

Atualmente, podemos dizer que:

A supervisão pedagógica dirige-se ao ensino e à aprendizagem. O seu objeto é a qualidade do ensino, porém os critérios e a apreciação da qualidade não são impostos de cima para baixo numa perspectiva de receituário acriticamente aceito pelos professores, mas na interação entre supervisor e os professores. (ALARCÃO, 2002 p. 12).

A abrangência do trabalho da supervisão compreende o currículo escolar, o planejamento, a avaliação, a metodologia de ensino, as estratégias de recuperação, as relações entre pessoas que constituem o coletivo da escola, especialmente professor-aluno, o cumprimento das normas legais, a formação continuada dos professores e outras 
Expectativas de Interação entre o supervisor pedagógico e o professor: controle ou autonomia

questões. É claro que esses aspectos não são exclusivos da Supervisão, mas essa função articuladora é, atualmente, ligada à ação da Supervisão.

Libâneo (2001, p.111) destaca que o Parecer 252/69 reproduz a ideologia implícita na Reforma Universitária de 1968, pois através das habilitações estaria introduzindo na escola "a divisão do trabalho e o controle segundo o modelo da administração capitalista", o que consequentemente acabou gerando a fragmentação da prática pedagógica.

Saviani (2002, p. 29) afirma que esse parecer representa "a tentativa mais radical de se profissionalizar a função do Supervisor educacional", pois estavam preenchidos os dois requisitos essenciais que marcam a transição de uma atividade para uma profissão, que são: a existência de um mercado de trabalho e a especificação das características da profissão ordenadas em torno de um mecanismo, tratadas no Parecer e instituídas no curso de Pedagogia.

Silva afirma que o referido Parecer 252/69

[...] reflete as linhas mestras do movimento de 64, buscando ser coerente com os princípios doutrinários do regime vigente. [...] é rico em justificativas para determinar que se siga uma ideologia. [...] utilizam-se de disciplinas que possam inculcar essa ideologia. [...] caracteriza o Supervisor, na linha economista transpostas do país hegemônico (EUA), como agente responsável pelo controle e execução da ideologia do poder. (SILVA, 2000, p. 69).

A supervisão pedagógica, numa perspectiva histórica, é também abordada por Saviani (2000). O autor faz um estudo sobre o modo que essa ação se faz presente na vida do ser humano desde as comunidades primitivas, passando pela manifestação da ideia na educação brasileira trazida pelos jesuítas, e analisa, finalmente, seu percurso desde os anos vinte até a década de oitenta. Saviani acredita na possibilidade de uma nova identidade para a ação supervisora, a ser construída a partir de um trabalho coletivo, fundamentado na complexidade característica da escola, e conclui, ainda pela análise histórica, que a questão da identidade do supervisor educacional continua em discussão no contexto atual. 
Aparecida A. BARBOSA; Cínara Gomes da SILVA; Sulamita C. R. do NASCIMENTO

Com a política dos acordos internacionais entre Brasil e Estados Unidos surge, em 1957, o Programa de Assistência BrasileiroAmericana ao Ensino Elementar - PABAEE 2, cuja importância é fundamental na determinação do modelo de supervisão tecnicista exercida no país desde a década de 60 . Se até essa época a função de supervisão era fortemente vinculada à fiscalização e comumente confundida com a inspeção escolar, agora a ação supervisora volta-se para o currículo escolar, sob a justificativa de buscar a melhoria da qualidade do ensino.

Especificamente sobre a influência do PABAEE na construção da identidade da profissão em Minas Gerais, Paiva e Paixão também contribuem com seus estudos, e nos dizem que

A supervisão que se dissemina com a ajuda do PABAEE supervaloriza métodos de ensino das disciplinas como questões fundamentais, em detrimento de uma análise mais ampla das causas dos problemas da escola primária. (PAIVA E PAIXÃO, 1997, p. 56).

Para Paiva e Paixão (2003), a modernização do ensino primário, na perspectiva do programa, seria trazer para o Brasil as inovações no campo da metodologia das áreas de ensino existentes nos Estados Unidos. E os professores considerados multiplicadores adequados para disseminar essas inovações seriam os formadores de professores, ou seja, os que atuavam nas Escolas Normais.

Sob o ponto de vista das relações de trabalho, a categoria "autonomia" aparece em vários estudos, como meta a ser alcançada e como determinante da qualidade do trabalho docente. Para analisar autonomia, Ferreira (2002, p.32), parte da premissa de que a supervisão é uma "[...] profissão organizacional". Nesse sentido, propõe um modelo de profissão (limitada em seu âmbito de alcance) que seja combinada com uma autonomia colegiada e participativa. Segundo a autora, a participação coletiva no projeto educacional tem

${ }^{2}$ Em 11/04/56, conforme Paiva e Paixão (2003, p. 37) o Ministério da Educação e Cultura solicita assistência técnica à Missão Norte-Americana de Cooperação Técnica no Brasil (Usom - B) para criação de um centro experimental de programa piloto de educação elementar em Belo Horizonte. Esse acordo foi assinado com a universidade de Indiana para a realização de cursos para brasileiros que viriam a atuar naquele programa. O acordo existiu de 1957 a 1964. 
Expectativas de Interação entre o supervisor pedagógico e o professor: controle ou autonomia

como meta a construção de um mundo "justo, solidário e humano." (FERREIRA, 2002, p. 42).

A autonomia limitada, a que se refere Ferreira, é um conceito trabalhado por Morin (2002), ao tratar de uma autonomia relativa, "que depende de seu meio ambiente, seja ele biológico, cultural ou social". O autor afirma que

[...] nós, seres culturais e sociais, só podemos ser autônomos a partir de uma dependência original em relação à cultura, em relação à língua, em relação a um ser. A autonomia não é possível em termos absolutos, mas em termos relacionais e relativos. (MORIN, 2002, p. 118).

Medeiros (apud SILVA JÚNIOR; RANGEL, 1997, p. 129-130) afirma que autonomia não se constrói pelo conhecimento meio, mas pelo conhecimento fim, e que a "emancipação e a autonomia só podem ser entendidas como legítimas se, em suas dimensões de "autenticidade', de 'verdade' e de 'justiça' contemplarem a todos e a cada um". Segundo Castoriadis (apud SILVA JÚNIOR; RANGEL, 1997, p. 40), "o especialista só tem sentido se nas suas ações estiverem implícitas as dimensões de co-gestão, de respeito ao outro e da busca da autonomia". Na mesma perspectiva do trabalho coletivo e da construção da autonomia de Medeiros, Castoriadis acredita que "se a busca de verdades sobre o mundo contrapuser homem e mundo, homem e outros homens, abrem-se possibilidades de controle de um sobre o outro homem." (apud SILVA JÚNIOR; RANGEL, 1997 p. 140).

Contreras (2002, p. 33) defende a tese de que "o trabalho docente sofreu uma subtração progressiva de uma série de qualidades que conduziram os professores à perda de controle sobre o próprio trabalho, ou seja, à perda da autonomia". Em suas análises sobre o tema, o autor pretende "aprofundar o entendimento de uma autonomia como chave para a compreensão de um problema específico do trabalho educativo" (CONTRERAS, 2002 p. 89), sem se deter no significado que a categoria apresenta como valor humano ou característica profissional. Assim sendo, analisa a autonomia mediante as novas políticas educacionais e conclui que autonomia não é desintegração e nem tampouco individualismo competitivo, mas "a convicção de que um desenvolvimento mais educativo dos professores e das escolas 
virá do processo democrático de educação, isto é, da tentativa de se construir autonomia profissional juntamente com autonomia social." (CONTRERAS, 2002 p. 275).

A definição de "autonomia" traz conceitos interessantes para esta pesquisa. Tendo em vista o tema da investigação, ou seja, a interação entre o supervisor pedagógico e o professor, e considerando a recorrência da ideia de autonomia nos estudos até agora analisados sobre o tema, a categoria reafirma-se importante inclusive pelo seu significado, ou seja, pela "dependência recíproca dos elementos de um todo, quer se trate de um organismo vivo ou de uma sociedade". A referência à reciprocidade como elemento constituinte do processo de construção das identidades de profissionais da educação mostra-se, em alguns estudos, como uma meta a ser alcançada na escola.

\section{ANÁLISE DAS RELAÇÕES}

Considerando o aspecto relacional deste estudo, os temas recorrentes nos depoimentos dos atores foram interpretados, em sua maioria, também de forma relacional, ou seja, a forma como é percebida a profissão, pelos atores, na relação entre o supervisor pedagógico e o professor.

\section{CONTROLE OU AUTONOMIA}

Tendo em vista a subjetividade dos atores e a definição da palavra "percepção", ou seja, o "ato de formar mentalmente representações sobre objetos externos a partir de dados sensoriais" (JAPIASSÚ, 1996), cuidou-se, na análise dos dados, de ouvir a voz dos atores, buscando-se interpretá-la a partir do próprio discurso e também do conteúdo, fundamentado teoricamente, com o objetivo de contextualização histórica e de significado.

As percepções, a princípio, refletem, em parte, a influência da formação adquirida pelos participantes, sobretudo pelas supervisoras, nos diferentes períodos focalizados pela pesquisa. A supervisora que trabalhou na escola pesquisada, na década de 70, enfatiza bastante um curso do qual participou junto com professores que atuaram nas quatro séries iniciais do Ensino Fundamental, aprendendo técnicas e métodos de ensino, quando relata: 
Expectativas de Interação entre o supervisor pedagógico e o professor: controle ou autonomia

Este curso foi um dos melhores cursos que já fiz até hoje, ele enfatizava o desempenho do aluno com baixo rendimento e na área de alfabetização em como trabalhar com alunos com dificuldades [...]

Os professores da base nacional comum eles trabalham a matéria e quando saímos do curso tivemos uma formação bem voltada para a formação do professor de $1^{a}$ a $4^{a}$ série.

Freitas (1999, p. 94) observou que a tentativa de envolvimento do professor faz parte de um plano para colocar a educação a serviço de novos padrões.

O Estado - legítimo representante dos interesses do capital - sabe que os professores são peças fundamentais na reestruturação da escola e, sem o envolvimento destes, qualquer reformulação está condenada ao insucesso - daí seu permanente esforço para cooptá-lo.

Essa tendência, chamada de pedagogia tecnicista, "foi assumida oficialmente, a partir de 1969, pelo aparelho do Estado, visando a sua implementação em todo o país." 3

Os cursos de formação de educadores promovidos pelo Instituto de Educação, na década de 70, estavam, nesse período, sob a influência da visão taylorista ${ }^{4}$ introduzida em 1927, pela Reforma Francisco Campos. Essa influência foi acentuada com a implantação do PABAEE, em 1956, cujo centro piloto foi instalado no Instituto de Educação de Belo Horizonte, como foi apontado nos aportes teóricos desta pesquisa. Segundo Paiva e Paixão (2002),

a perspectiva tecnicista orientou toda atuação do PABAEE, [...] e o currículo dos cursos de treinamento foi construído a partir da aposta de que os problemas do

\footnotetext{
3 Trecho extraído do texto redigido a partir da pesquisa "História das ideias pedagógicas no Brasil", desenvolvida por Saviani em 2000.

${ }^{4}$ Para Taylor, passa a ser de competência da gerência o controle do modo concreto de execução de toda a atividade no trabalho, desde a mais simples até a mais complexa, isto é, o controle do trabalho através do controle das decisões que são tomadas no curso do trabalho. (SILVA apud FERREIRA, 1998, p. 42-43).
} 
ensino primário poderiam ser enfrentados com a difusão de métodos adequados e modernos de ensino.

De acordo com Saviani (2002), o planejamento do processo pedagógico ficava controlado pelos técnicos supostamente habilitados, e os professores passavam a um plano secundário, ficando subordinados à organização racional dos meios, entendidos como técnicas de aprendizagem e material didático previamente elaborado. Imbuída da função de controle, a supervisão foi exercida de cima para baixo, de forma paternalista.

A expressão "como trabalhar" proporcionava à supervisora a possibilidade de garantir que os professores agissem conforme um modelo externo do método aprendido, ou seja, sobre o que era certo ou errado. A diferença de saberes, hierarquicamente organizada na escola, seria, portanto, a justificativa para a postura "paternalista" da supervisora, que se investia de um poder entendido como "prerrogativa de exigir de outrem a prática de certo ato para controlar a prática do professor e legitimar seu papel". (FERREIRA, 1986).

A legitimação da supervisão pode acontecer, em parte, pela relação e, em parte, pela forma como se dá essa relação. E ambos os aspectos são relevantes também para os professores, os quais, em sua maioria, acreditam no poder da relação, mas discordam da forma que ela acontecia na escola, uma vez que era apoiada na hierarquização das posições e no princípio do controle. Não é o controle que caracteriza a ação, mas sim a solidariedade, que a legitima pela aproximação que proporciona entre o supervisor e o professor e pelo resultado positivo no trabalho pedagógico como um todo, conforme relata o professor Elton:

Como professor sempre fui e sempre cobrei, via esses aspectos de supervisor também naquilo que a gente falou de afeto, da orientadora e supervisora na sala de aula, tudo também depende do modo que ela chega. Você cativa o professor, aí eu passo a acreditar, aí você vai passar a receber bem, eu posso pensar que realmente você quer me ajudar. Mas de repente você pode pensar que isso vai de pessoa para pessoa, você passa a me criticar e às vezes você começa a forçar uma barra, como já teve um caso de alguns funcionários da delegacia que iam assistir à aula do professor, etc. e tal [...]. 
Expectativas de Interação entre o supervisor pedagógico e o professor: controle ou autonomia

Apesar de apontar probabilidades de procedimentos negativos na relação supervisor/professor ("você passa a me criticar e às vezes você começa a forçar uma barra"), o professor Elton mostra em seu discurso uma representação positiva da supervisão, enxergando na ação por ela desenvolvida, inclusive, a possibilidade de aquisição de qualidade no trabalho pedagógico. É o que também enfatiza o professor Valter, referindo-se a "um apoio" alcançado pela referida relação, quando solidária:

[...] uma escola não funciona sem supervisão, não tem jeito de funcionar, não tem, não há condição de funcionar. Porque é muito grande esta escola, mesmo ela sendo pequenininha, essa é a pessoa de apoio que você tem para desabafar, você precisa de vez em quando, você está com problema com aluno, você leva prá supervisão e prá orientação. Eu estou com esse problema, então eu acho que ela resolve o problema nosso, que é dos professores, e ajuda o aluno também.

Para o professor Valter, tal "apoio" estaria na ajuda prestada pelo supervisor ao docente, ajuda essa que pode significar uma orientação, uma informação técnica ou até mesmo a elaboração conjunta de uma avaliação. Nas palavras da professora Heliane,

[...] a figura do supervisor não é uma pessoa que entende de todas as matérias, então para ele pegar uma prova de física, química, matemática, história para analisar bem cientificamente é difícil, mas ele deve ter noção do que é uma prova bem elaborada, ou seja, como ela foi feita, se ela está clara para o aluno, se é objetiva. Eu acho isto muito importante, mas lamentavelmente nem todos os professores aceitam o trabalho do supervisor, perdem a ajuda para o crescimento.

Essa professora vincula a prática da supervisora ao conteúdo das disciplinas na escola e, também, ao saber relacional. Ela compreende, segundo seu depoimento, que não há necessidade de o supervisor ter um conhecimento generalista, ou seja, dominar todos os conteúdos das diversas disciplinas para trabalhar com o professor. 
Aparecida A. BARBOSA; Cínara Gomes da SILVA; Sulamita C. R. do NASCIMENTO

Considera que esse apoio poderia vir de outra forma, em como se dá essa relação. É um saber relacional.

O sentimento positivo da professora Heliane é compartilhado com o professor Valter, que trabalhou na escola durante os dois períodos pesquisados e conviveu tanto com as primeiras supervisoras como com a atual. Ele percebe a ação supervisora como necessária para a realização do trabalho pedagógico, e o aspecto positivo de sua percepção está ligado ao sentido relacional. Ou seja, a supervisão é reconhecida como apoio, cujo conceito, para o professor, fundamentase no comprometimento do profissional:

Eu acho que a escola não consegue sobreviver sem o orientador, sem o supervisor, porque essas pessoas são o suporte de apoio que a gente tem na escola, então a gente precisa muito desse profissional dentro da escola. A gente precisa muito dele, mas ele precisa ser bem comprometido com o trabalho [...]. Essas pessoas são fundamentais na escola, supervisor, a parte pedagógica, a escola precisa recebê-los com bastante carinho [...].

A supervisora Augusta confirma a percepção do professor Valter e assume o papel de agente de uma transição do enfoque administrativo e burocrático para o enfoque que, para ela, caracteriza mudança.

$\mathrm{Ah}$ ! Eu fico feliz, porque percebo que eles gostam do meu trabalho e sentem falta do mesmo. [...] Estamos sempre conversando e trocando idéias e isto é gratificante. [...] Penso que de maneira alguma pode faltar no ambiente escolar o calor humano, essa proximidade é fundamental para um bom funcionamento, ou seja, um relacionamento com todo o pessoal da escola.

A supervisora insere-se no processo de mudança pelo uso da autonomia, o que lhe confere um poder de autoridade, porém uma autoridade libertadora ${ }^{5}$, que permite e motiva a mudança. Segundo a interpretação de Contreras (2002, p. 186),

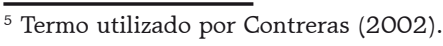

Olhar de professor, Ponta Grossa, 12(2): 331-357, 2009.

Disponível em <http://www.uepg.br/olhardeprofessor> 
Expectativas de Interação entre o supervisor pedagógico e o professor: controle ou autonomia

parece que o processo de emancipação do professor depende da figura de uma autoridade libertadora, quer dizer, de alguém (seja uma pessoa, um texto ou uma teoria) que represente o conteúdo dos ideais de liberdade, igualdade e democracia, bem como os modos de razão que não são formas distorcidas de pensamento.

O papel do supervisor, de colaborador no processo de construção da autonomia do professor, foi percebido também pelo diretor da escola na década de 80, Márcio:

[...] A direção aceitava e gostava porque era uma ajuda, por outro lado é uma forma legal, tem de aceitar de qualquer maneira, mas não foi pela forma legal, foi pela forma de autonomia e vantagem pela escola. Então eu notava que não havia problema; pelo contrário, havia uma aceitação muito grande do supervisor.

A percepção da profissão como integradora, no processo pedagógico, aparece como um consenso entre os atores que trabalharam na escola no período de 70 , sobretudo ao analisarem a ação da supervisão nas reuniões pedagógicas.

Assim como o diretor Márcio, a supervisora Waldete já definia a própria ação como mediadora da interdisciplinaridade. Ao explicar a dinâmica dos encontros realizados entre ela e os professores, Waldete afirma que sempre dedicou a maior parte do tempo das reuniões à troca de experiências entre os professores e à valorização desses profissionais..

Eu procuro muito mostrar o sucesso do professor também, a valorização. Igual agora, no momento que a escola foi valorizada. Nós estamos montando uma reunião para mostrar o que aquele professor representa, a importância do professor, então todo o nosso trabalho é realizado dessa forma.

Contreras (2002, p. 98) considera a criatividade e os elementos que dela derivam como 
"a intuição, a improvisação e a tentativa, como um componente artístico da prática docente que deve ser considerado como válido e importante para a solução dos problemas do cotidiano". E é nesse sentido, ou seja, com base no cotidiano, que acontecem as reuniões pedagógicas, as quais se transformam num espaço para a reflexão teórica sobre a prática intuitiva.

A existência de um referencial externo para a tomada de consciência dos professores é uma das perspectivas que orienta Contreras na definição de autonomia como processo progressivo de emancipação. Segundo o autor:

[...] os próprios processos de reflexão crítica e de emancipação parecem necessitar inevitavelmente de influências externas, seja em forma de teorias críticas que formulam as leituras adequadas dos fenômenos da vida social e do ensino que devem ser modificados, seja em forma de 'ilustradores' que trazem o referido conhecimento e colaboram na auto-reflexão dos docentes para que superem suas distorções ideológicas. Isso é, nos tempos de Giroux, parece que o processo de emancipação dos professores depende da figura de uma 'autoridade libertadora', quer dizer, de alguém (seja uma pessoa, um texto ou uma teoria) que represente o conteúdo dos ideais de liberdade, igualdade e democracia, bem como os modos de razão que não são formas distorcidas de pensamento. (CONTRERAS, 2002, p. 186 - 187).

A aceitação do poder libertador da supervisora não ameaça os professores, pela sua própria condição de serem professores. As quatro paredes da sala de aula representam uma barreira forte o suficiente para protegê-los até mesmo de suas possíveis fraquezas. De certa forma, imunes ao controle, os professores procuram a supervisão, movidos pelo desejo, e somente em função dele a relação é acionada, conforme relata a professora Samanta:

[...] eu não dou trabalho em disciplina e nem em nada. Eu não tenho nada a reclamar, que tenha contato profissional. Mas ela (supervisora) dá apoio para quem precisa, na hora que precisa ela dá. 
Expectativas de Interação entre o supervisor pedagógico e o professor: controle ou autonomia

O trabalho fundamentado nas relações faz com que a supervisora Waldete perceba uma outra possibilidade de atuação em seu trabalho, além daquela que é esperada e já realizada, junto ao professor. Trata-se da relação do professor com o aluno.

[...] essa supervisão ela é um elo que tem entre o professor e o aluno, entre o professor e supervisor ou professor que posteriormente liga o elo ao aluno, então sempre se tem um contato. E todo o trabalho do professor é voltado em melhorias.

Tanto o professor como o aluno ficam mais próximos do sucesso quando o trabalho é realizado coletivamente, e essa idéia é compartilhada pela diretora Denise.

[...] eu tinha um professor que recortava questões de livro e colava ali na prova aleatoriamente. E com isso o aluno nem sabia o que fazer, às vezes tinha que virar a prova de cabeça para baixo, ou do lado para ler a questão. Para mim, isto é uma falta de ética, às vezes o aluno nem sabe ler direito e ainda encontra um trabalho desse jeito [...] agora tem uns que não, já procuram estar em consonância com o que a supervisão propõe, procuram fazer as coisas com capricho e tudo, dentro da didática, elaborando provas no nível que faça o aluno pensar, raciocinar, porque não é só chegar lá e marcar um x.

Pelo olhar de Marília, supervisora da primeira década desta pesquisa, além de estar ligada direta e indiretamente ao aluno, a supervisora adquire, ainda, um outro espaço de atuação, os afazeres da supervisão, segundo o que lhe é cobrado pela Secretaria de Estado da Educação, via Superintendência Regional de Ensino:

Nós nos reuníamos com um representante da superintendência que era o Pedro e com um coordenador da área pedagógica, de vez em quando ele cobrava serviço, acompanhava as experiências e os relatórios e também eles vinham à escola para ver se o projeto estava dando 
Aparecida A. BARBOSA; Cínara Gomes da SILVA; Sulamita C. R. do NASCIMENTO

certo. O projeto tinha de estar trabalhando dentro do que a Secretaria estava colocando, porque ela investiu em todas as escolas e no magistério do Estado de Minas Gerais.

Os representantes não se envolviam, só faziam parte de reuniões. Em dias letivos costumava vir uma equipe da Secretaria para uma visita, e isso era algo de costume, conversavam com o professor, com o diretor, com o especialista. Reuníamos-nos e colocávamos tudo aquilo que estávamos sentindo.

Podemos perceber na fala da supervisora Marília indícios de um pensamento global, voltado para a promoção do trabalho coletivo, mas ao mesmo tempo isolado, quando ela relata que os representantes da Superintendência de Ensino não se envolviam. As expressões nós nos reuníamos e não se envolviam, pelas suas contradições, parecem representar o ideal e o real, respectivamente. A supervisora demonstra, por meio delas, a fragmentação do trabalho realizado, ao mesmo tempo em que reconhece o esforço da supervisora no sentido de desenvolver seu trabalho e contar com o apoio do órgão oficial.

No atual momento da ação pedagógica do supervisor na escola, a professora de Língua Portuguesa Andréa faz observações sobre outros afazeres da supervisora e comenta:

Hoje eu percebo que há mais trabalho por parte da supervisão, só que eu vejo que é muito mais administrativo que pedagógico. Sabe, que é muito, pelo menos nesta área de quinta à oitava e Ensino Médio, que eu vejo mais administrativo que pedagógico.

A professora percebe que o tempo da supervisão, que deveria ser utilizado na relação com o professor, está atualmente direcionado, em grande parte, ao cumprimento da burocracia administrativa. Dessa forma, o trabalho da supervisão com o professor fica sendo esporádico, diminuindo a possibilidade de interação com os professores.

A cumplicidade pedagógica, além de possibilitar apoio para as decisões e escolhas do professor, representa proteção em relação à comunidade escolar, sobretudo perante os pais, ao questionarem, 
Expectativas de Interação entre o supervisor pedagógico e o professor: controle ou autonomia

eventualmente, as abordagens pedagógicas definidas pela escola. $\mathrm{O}$ professor idealiza encontros mais sistematizados e organizados no sentido da constante interação, pois é daí, do contato, que surge a cumplicidade e o consequente compromisso entre as pessoas e delas com a escola.

Esse sentimento de cumplicidade que se encontra na relação supervisor/professor distancia-se, portanto, de qualquer compromisso hierárquico de poder e controle que tenha caracterizado algumas relações de profissionais do primeiro período da pesquisa. Hoje a relação com a supervisão é desejável, pois representa, ao salvar, uma aproximação do sucesso, pela possibilidade de afastamento da solidão, característica da profissão docente quando exercida de forma fragmentada.

A palavra solidão traduz situações vividas pelos atores dos dois períodos da pesquisa que se tornaram, pelo sofrimento causado, motivo do desejo dos professores da escola pesquisada por uma adequada relação com a supervisão. Ora idealizada, ora vivida, a profissão é sempre percebida como necessária $\square$ e, assim, como positiva $\square$ por todos os atores entrevistados.

Confrontando o real com o ideal, os atores do primeiro período histórico, década de 70, apoiam-se na supervisão existente, paternalista e controladora, para sonhar com a companhia pedagógica ideal. Os atores do período atual percebem, em sua relação com a supervisão, as características desejadas pelos atores do primeiro período e propõem, inclusive, uma intensificação dessa relação, pela qualidade adquirida no processo pedagógico e para o progresso pedagógico.

\section{CONSIDERAÇÕES FINAIS}

Conforme anunciado na introdução deste texto, o nosso propósito foi investigar a relação do supervisor pedagógico e o professor, na tentativa de, conhecendo as expectativas dos profissionais, entender a razão de uma ação pedagógica supostamente conjunta e analisar sua influência no trabalho pedagógico como um todo. A literatura especializada embasou o nosso estudo e tornou-se importantíssima para as análises que passaremos a fazer.

Vimos que a função de supervisão sofreu e sofre ainda várias mudanças em seu foco de atuação. É uma função que nasceu ligada à fiscalização e ao controle e foi muitas vezes confundida com inspeção 
Aparecida A. BARBOSA; Cínara Gomes da SILVA; Sulamita C. R. do NASCIMENTO

escolar. Devido ao acordo PABAEE entre Brasil e Estados Unidos, sofreu uma adequação ao modelo tecnicista de ensino.

A função de controle e fiscalização era extremamente necessária ao sistema de governo. Aproprio-me das palavras de Silva Júnior (2003, p.93), quando qualifica a atuação da supervisão escrevendo que "para uma sociedade controlada, uma educação controlada; para uma educação controlada, um supervisor controlador e também controlado".

$\mathrm{Na}$ análise das entrevistas utilizamos a técnica de análise dos conteúdos, partindo da elaboração de recortes nas referidas falas e, posteriormente, chegando a uma análise entre elas e à realização do texto através das falas. .

Nas falas dos atores entrevistados chamou-nos a atenção as várias vezes em que surgiu a palavra "apoio". O saber relacional, percebido como apoio, tem valor de suporte para ambos, professor e supervisor. As supervisoras acreditam que o sucesso de seu trabalho depende, sobretudo, das relações pessoais, cuja qualidade definirá as possibilidades e os limites de atuação. Sendo político, o desafio é então $\square$ segundo o princípio político aristotélico $\square$ organizar uma existência coletiva.

Um trabalho fundamentado nas relações faz com que os atores percebam uma outra possibilidade de atuação em seu trabalho, além daquela que é esperada e já realizada junto ao professor. Trata-se da relação do professor com o aluno, ficando ambos mais próximos do sucesso.

Isso leva a crer que não há mais possibilidade de existirem ilhas isoladas, assim como é inadmissível que supervisores e professores sintam-se presos a padrões de comportamento preestabelecidos e cristalizados, a um passado que hoje não faz sentido. Além do mais, não há necessidade de haver a "solidão" que tanto incomoda os atores entrevistados.

Acabou o tempo em que se confundia autonomia com individualismo e a aproximação entre a supervisora e os professores tinha o objetivo de controle do trabalho, supervalorizando-se o aspecto formal e burocrático em detrimento do relacional e criativo. O contato entre a unidade e a multiplicidade acontece no espaço da relação, em busca de um conhecimento significativo, ou seja, de um conhecimento que permite ao indivíduo enfrentar os desafios da complexidade, trabahado 
Expectativas de Interação entre o supervisor pedagógico e o professor: controle ou autonomia

por Morin $(2002)^{6}$. O desafio que se faz, por meio da relação e da organização, é o da interação, da promoção da interdependência das partes entre elas e delas com o todo, mantendo-as diferentes para que, na diferença, tenham o que trocar.

Ambos, supervisores e professores, acreditam no poder da relação, mas discordam da forma como ela acontecia na escola, ou seja, apoiada na hierarquização das posições e no princípio do controle.

A gestão democrática do trabalho pedagógico, afirma Freitas (2001, p.191), foi concebida por Paulo Freire "como o caminho possível de reinvenção da escola, tendo em vista a construção de sua qualidade democrática". Essa postura decorre da concepção libertadora da educação, que entende o comprometimento de todos como condição para transformação, uma vez que o sujeito só se responsabiliza por aquilo que ele conhece e ajudou a fazer.

Nessa perspectiva, a supervisão escolar também precisou ser reinventada, recriada, tendo sua centralidade não mais na tarefa e sim na reflexão. A necessidade de estudarmos sobre a supervisão cresce proporcionalmente com a complexidade das tarefas atribuídas à escola hoje. Revermos nossas práticas e colocá-las em diálogo com diferentes referenciais teóricos é fundamental para a garantia de um fazer significativo.

Dessa forma, o material aqui reunido pode servir de ponto de partida para outros estudos, para subsidiar novas reflexões. A importância de conhecer o passado reside exatamente em melhor compreender o presente e poder entender o futuro como possibilidade. Nas palavras de Paulo Freire (1999 p. 85): "É o saber da História como possibilidade e não como determinação. $O$ mundo não é. $O$ mundo está sendo. [...] o meu papel no mundo não é só o de quem constata o que ocorre, mas também o de quem intervém como sujeito de ocorrências". Entender-se como sujeito que está no mundo e com o mundo é entender-se como sujeito que pode provocar mudanças, que tem a oportunidade de fazê-lo. Ou seja, nós, supervisores, entendendo-nos como profissionais que estamos nas escolas, com as escolas, temos, diariamente, a possibilidade de fazermos a diferença com nossa intervenção ou com nossa omissão, pois "Ninguém pode estar no mundo, com o mundo e com os outros de forma neutra." (FREIRE, 1999, p. 86).

${ }^{6}$ Complexo, segundo o autor, vem do latim complexus, significa 'aquilo que foi tecido junto' e deve ser o paradigma da educação do futuro. 
Muitas vozes aqui foram ouvidas (certamente nossos ouvidos não deram conta de ouvir tudo!), e muitas vozes ficaram mudas. Temos consciência da inconclusão, mas não tínhamos intenção em concluir este estudo de forma definitiva, pois acreditamos que ele não deve ser (e não foi!) realizado individualmente, sobretudo porque fala de práticas coletivas e, portanto, busca a presença de outros.

Em se tratando da supervisão, os depoimentos dos atores desta pesquisa evidenciam, também, a importância de ações coletivas no cotidiano escolar e mostram que, em educação, há que se tratar do coletivo em oposição à fragmentação, há que se entender de comprometimento, há que se viver acompanhado e há que se trocar o controle pela autonomia.

\section{REFERÊNCIAS}

ALARCÃO, I. Do olhar supervisivo ao olhar sobre a supervisão. In: RANGEL, M. (Org.). Supervisão pedagógica: princípios e práticas. 3 ed. Campinas: Papirus, 2002.

ARROYO, M. G. O ofício de mestre: imagens e auto-imagens. 3 ed. Petrópolis: Vozes, 2000.

BRASIL. Parecer 252, de 11 de abril de 1969. Estudos pedagógicos superiores. Mínimos de currículo e duração para o curso de graduação em Pedagogia. In: SILVA, N. S. F. C. Supervisão educacional: uma reflexão crítica. 10 ed. Petrópolis: Vozes, 2000.

. Resolução CNE/CP n ${ }^{\circ}$ 1, de 15 de Maio de 2006. Institui Diretrizes Curriculares Nacionais para o Curso de Pedagogia, licenciatura. Diário Oficial da União. Brasília, 16 de maio de 2006. Seção1, p. 11.

. Resolução no 2, de 12 de maio de 1969. Fixa os mínimos de conteúdo e duração a serem observados na organização do curso de Pedagogia. In: SILVA, N. S. F. C. Supervisão educacional: uma reflexão crítica. $102 \mathrm{~d}$. Petrópolis: Vozes, 2000.

. Lei $\mathrm{n}^{\circ}$ 9.394, de 20 de dezembro de 1996. Estabelece as diretrizes e bases da educação nacional. Diário Oficial, Brasília: v. 134, n 248, 23 dez. 1996.

. Lei $\mathrm{n}^{\circ}$ 5.692, de 11 de agosto de 1971. Fixa as diretrizes e bases para o ensino de $1^{\circ}$ e $2^{\circ}$ graus e dá outras providências. In: Câmara dos Deputados. Breviário da legislação federal da educação e cultura. Brasília: 1978. 
Expectativas de Interação entre o supervisor pedagógico e o professor: controle ou autonomia

CASTORÍADES, C. A instituição imaginária da sociedade. Rio de Janeiro: Paz e Terra, 1982.

CONTRERAS, J. A autonomia de professores. São Paulo, Cortez, 2002.

FERREIRA, A. B. H. Novo dicionário Aurélio da língua portuguesa. Rio de Janeiro: Nova Fronteira, 1986.

FERREIRA, N. S. C. (Org.). Supervisão educacional: para uma escola de qualidade. 3 ed. São Paulo: Cortez, 2002.

. Supervisão educacional: novas exigências, novos conceitos, novos significados. In: RANGEL, M. (Org.) Supervisão pedagógica: princípios e práticas. 3 ed. Campinas: Papirus, 2000.

FREIRE, P. Pedagogia da autonomia: saberes necessários à prática educativa. 12 ed. São Paulo: Paz e Terra, 1999.

FREITAS, L. C. Neotecnicismo e formação de educador. In: ALVES, N. (Org.). Formação de professores: pensar e fazer. 5 ed. São Paulo: Cortez, 1999.

JAPIASSÚ, H.; MARCONDES, D. Dicionário básico de filosofia. 3 ed. Rio de Janeiro: Jorge Zahar, 1996.

LIBÂNEO, J. C. Que destino os educadores darão à pedagogia? In: PIMENTA, S. G. (Coord.). Pedagogia, Ciência da educação? 4. ed. São Paulo: Cortez, 2001.

MALDONADO, M. B. O professor e o supervisor pedagógico: solidão ou solidariedade? 2003. Dissertação (Mestrado em Educação) - PUC, Minas Gerais, 2003.

MARCUSE, H. A ideologia da sociedade industrial. 6 ed. Rio de Janeiro: Zahar Editores, 1982.

MEDEIROS, L. Supervisão educacional: possibilidades e limites. São Paulo: Cortez/Autores Associados, 1987, 95p.

MOREIRA, A. F. B. A formação de professores e o aluno das camadas populares: subsídios para debate. In: ALVES, N. (Org.). Formação de professores: pensar e fazer. 7. ed. São Paulo: Cortez, 2002.

MORIN, E. Os sete saberes necessários à educação do futuro. Tradução de Catarina Eleonora F. da Silva e Jeane Sawaya.. Brasília; Cortez, 2002.

PAIVA, E. V.; PAIXÃO, L. P. O PABAEE e o ensino primário: a assistência técnica norte-americana no Brasil nos anos cinquenta e sessenta. Rio de Janeiro, 1997. Relatório de Pesquisa. 
Aparecida A. BARBOSA; Cínara Gomes da SILVA; Sulamita C. R. do NASCIMENTO

. O PABAEE e a supervisão escolar. In: SILVA JÚNIOR, C. A.; RANGEL, M. (Org.). Nove olhares sobre a supervisão. 9 ed. Campinas: Papirus, 2003.

Sociedade e pesquisa: a americanização do ensino elementar no Brasil? Niterói: EDFF, 2002.

RANGEL, M. (Org.). Supervisão pedagógica: princípios e práticas. 3 ed. Campinas: Papirus, 2000.

SAVIANI, D. A supervisão educacional em perspectiva histórica: da função à profissão pela mediação da idéia. In: FERREIRA, N. S. C. (Org.). Supervisão educacional para uma escola de qualidade. 3 ed. São Paulo: Cortez, 2002.

. Educação brasileira: estrutura e sistema. 8 ed. Campina: Autores Associados, 2000.

SILVA JÚNIOR, C. A. Supervisão da educação: do autoritarismo ingênuo à vontade coletiva. 2 ed. São Paulo: Loyola, 1986.

; RANGEL, M. (Org.). Nove olhares sobre a supervisão. 9 ed. Campinas; Papirus, 1997.

; RANGEL, M. (Org.). Nove olhares sobre a supervisão. 9 ed. Campinas; Papirus, 2003.

SILVA, N. S. F. C. Supervisão educacional: uma crítica reflexiva. Petrópolis, Vozes, 2000.

SMYTH, J. Perspectivas internacionales sobre la colegialidad docente: un enfoque crítico basado en el concepto de enfoque crítico basado en el concepto de trabajo de los docentes. In: ANGULO RASCO et al. (Eds.) Desarrollo profesional docente: política, investigación y práctica. Madrid: Akal, p. 52-77, 1999.

Enviado em: 05/09

Aceito em: 08/09 